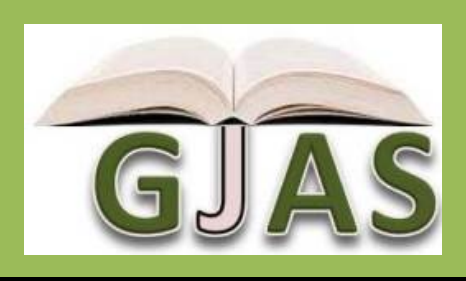

\title{
Evaluating the Potential of African Catfish (Clarias gariepinus) to Bioaccmulation of Some Selected Heavy Metals
}

\section{Femi Francis Oloye*, Isaac Ayodele Ololadea, Oluyinka David Oluwolea and Oluwabunmi Peace Oluyedeb}

${ }^{1}$ Adekunle Ajasin University Ondo State Nigeria.

${ }^{2}$ Suface Chemistry and Catalysis Group, University of Aberdeen, United Kingdom.

ARTICLE INFO

Article No.: 083013809

DOI: 10.15580/GJAS.2013.10.083013809

Submitted: 30/08/2013

Accepted: 22/10/2013

Published: 29/10/2013

${ }^{\star}$ Corresponding Author

Femi Francis Oloye

E-mail: pen2crown@gmail.com

Keywords:

Bioaccumulation, heavy metals,

seistic bioassays
The potential of African Catfish to bioaccumulation of some selected heavy metals was done by introducing heavy metals into the fish water after the fish was starved for $24 \mathrm{hr}$; the test was done by semistic bioassays method. The results were analysed with AAS and it was observed that different metals attached to various part of the fish with diverse strength and affinity.

ABSTRACT 


\section{INTRODUCTION}

Industrial wastes, geochemical structure and mining of metals create a potential source of heavy metal pollution in the aquatic environment [1,2]. In March 2010, an unusually high number of deaths, primarily among children under age 5 in Bukkuyum and Anka Local Government Areas (LGAs) of Zamfara State, northern Nigeria, was reported by Médecins sans Frontières (MSF-Holland) to state health authorities. Further study on blood samples taken by MSF revealed that the increased mortality was the result of acute lead poisoning, determined to be caused by massive environmental contamination from artisanal mining and processing of gold found in lead-rich ore. The grinding of the ore into fine particles resulted in extensive dispersal of lead dust in the villages concerned, including within family compounds. Ingestion and inhalation of the fine lead particles was determined to be the major reason for high blood lead levels in victims' bodies. Blood lead levels (BLLs) were "unprecedented" for human beings, according to the US Centers for Disease Control and Prevention (CDC).

In the sea, pollutants are potentially accumulated in marine organisms and sediments through bioaccumulation and bio concentration and consequently transferred to human being through food chain. The heavy metal pollution of the marine environment has long been recognised as a serious environmental concern $[3,4]$. Heavy metals could either be essential metals or non-essential metals depending on their toxicity and uses. Zinc, copper, iron, manganese and nickel are example of essential metals while lead, mercury and cadmium are examples of nonessential metals. It is of importance that essential metal could also become threatening and dangerous if it exceeds certain limits. In this study POTENTIAL OF AFRICAN CATFISH (Clarias gariepinus) TO BIOACCMULATION OF HEAVY METALS will be evaluated and necessary conclusion as regards parts of the fish with highest bioaccumulated metals will be made.

\section{EXPERIMENTAL}

\section{Sample collection and Acclimatization}

Healthy specimens of African catfish Clarias gariepinus were obtained from a local fish farm at Ikare-Akoko town, Ondo State, Nigeria and were transported in containers to the laboratory. The choice of Clarias gariepinus was informed by its ability to withstand stress and its high commercial value in Nigeria. In the laboratory, fishes were kept in large plastic bowls containing $60 \mathrm{~L}$ of clean tap water and acclimatized for 6 weeks to the laboratory conditions, during which time they were provided with artificial feed (grower's mash) and ground shrimps obtained locally to avoid possible effects of starvation on any of the parameters of the fish. The size of the fish varied from $18.1-22.7 \mathrm{~cm}$ in standard length and 50.6-97.4g in weight. Fish of both sexes were used without discrimination. The fish were inspected for disease conditions and general fitness.

Water was changed every other day. Fourteen fingerlings were kept per bowl. There were five different treatment groups and each had three replicates. The fish were fed three times daily on a 40-percent crude protein diet during the period of acclimatization. Feeding was discontinued while aeration continued during the 96-hr test period.

\section{Determination of Water Physico - Chemical Parameters}

The water quality parameters of the diluting water used in the tests were determined by standard methods [6]. The temperature was measured with mercury-in-glass thermometer. Measurements were made also of the $\mathrm{pH}$ using pre-calibrated pH meter (Hanna pH 211 microprocessor). The alkalinity and dissolved oxygen were also determined. The results are presented in Table 4.1.

\section{Preparation of Stock and Test Solutions of Zinc}

Stock solution of the test metal compound, a chemically pure copper tetraoxosulphate IV heptahydrate $\left(\mathrm{CuSO}_{4} .5 \mathrm{H}_{2} \mathrm{O}\right.$ ) was prepared by dissolving $3.906 \mathrm{~g}$ of Merck grade reagent equivalent to $1 \mathrm{~g}$ of zinc in 1000 $\mathrm{ml}$ distilled water at concentration of $1000 \mathrm{mg} \mathrm{L}^{-1}$ (i.e. $1000 \mathrm{ppm}$ ). From the stock solutions, $5.0 \mathrm{ppm}$ was prepared by pipeting $5 \mathrm{ml}$ of the stock and add to 995 $\mathrm{ml}$ of distilled water. This concentration was used in the study to assess not the mortality rate but the extent to which $\mathrm{Zn}$ can be taken up by the fish, its binding potential to the various organs and possibly, extent of recovery within a clean environment

\section{Toxicants Introduction}

The fishes numbering 30 , which have been starved for 24-hr was distributed into three 60L capacity plastic containers. To each container, ten fishes were introduced. The toxicant (5.0 ppm Zn solution) was introduced immediately and the time accurately recorded. The exercise lasted for 96-hr. and the mortality during the period were carefully noted and recorded. The test was performed by the semistic (renewal) bioassay method in which the exposure medium was exchanged every 24-hr to maintain toxicant strength and level of dissolved oxygen as well as minimizing the ammonia excretion levels during this experiment [5]. After the 96-hr expiration of the experiment, two fishes from each plastic were removed and preserved in the freezer for metal analysis.

\section{Recovery Study}

The fishes remaining after the 96-hr bioassay were transferred in a clean water inside similar plastic bowl, fed with fish meals and monitored for another 96-hr. After the 96-hr expiration of the experiment, two fishes from each plastic were removed again and preserved in the freezer for metal analysis. 


\section{RESULTS AND DISCUSSION}

The results of the physico-chemical parameters measured are given in table 3.1 while figure 3.1 to 3.2 gives the details of the concentrations of $\mathrm{Cu}, \mathrm{Cu} \& \mathrm{Zn}$, $\mathrm{Pb}$, and $\mathrm{Pb} \& \mathrm{Ni}$ in the various parts of the fish examined in the study, before and after recovery.

Table 3.1: The physico-chemical characteristics of the water used

\begin{tabular}{|l|l|}
\hline Parameter & Value \\
\hline Temperature $\left({ }^{\circ} \mathrm{C}\right)$ & $27.4 \pm 1.1$ \\
\hline $\mathrm{pH}$ & $6.51 \pm 0.23$ \\
\hline Alkalinity (as $\left.\mathrm{HCO}_{3}{ }^{-}\right)$ & $193.3 \pm 2.7$ \\
\hline Hardness (as $\left.\mathrm{CaCO}_{3}\right)$ & $227.5 \pm 3.1$ \\
\hline Dissolved oxygen & $6.56 \pm 1.23$ \\
\hline
\end{tabular}

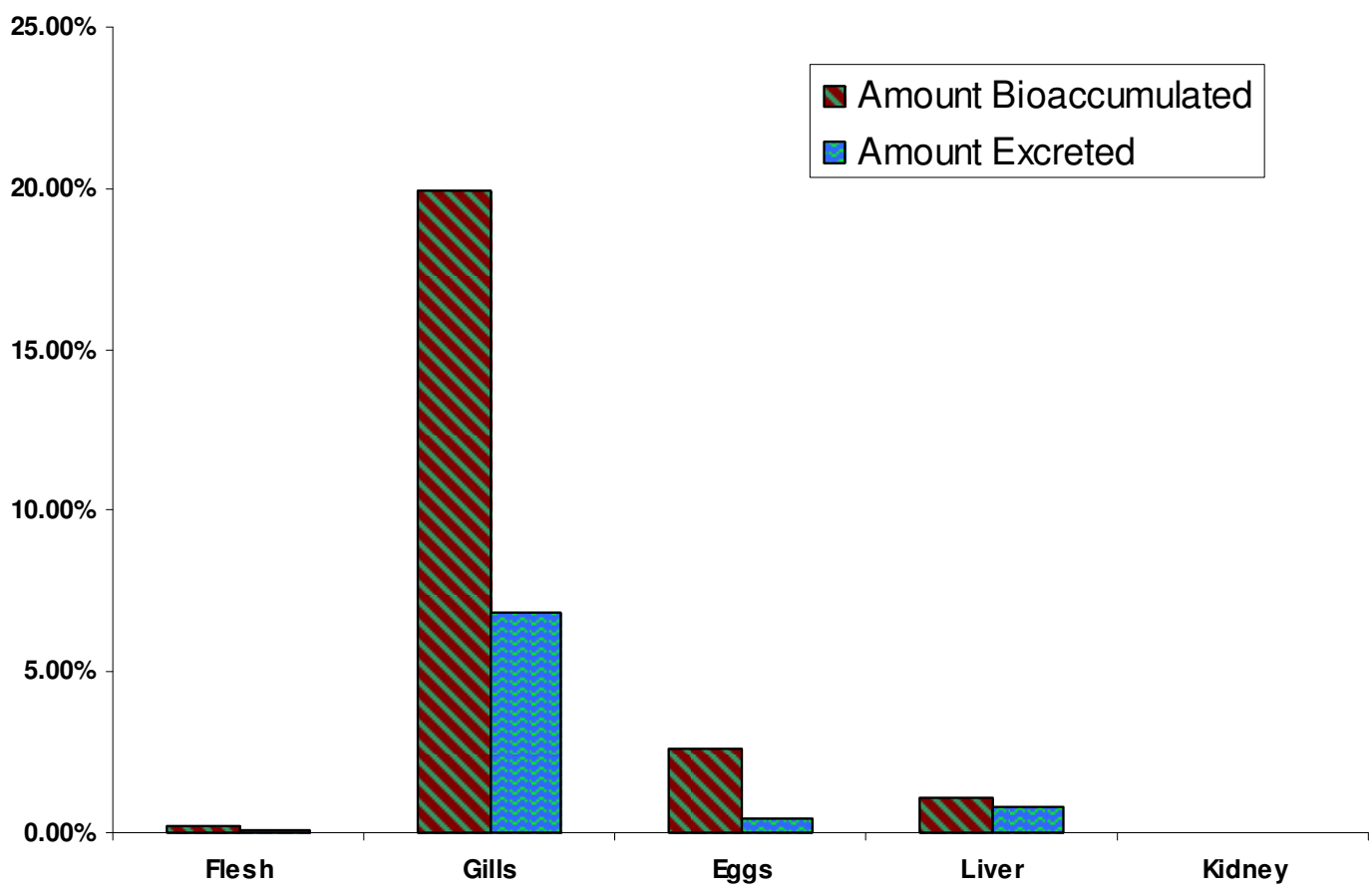

Fig. 3.1 Percent Cu bioaccumulated and excreted in fish.

It can be seen from fig.3.1 that the concentration of $\mathrm{Cu}$ in the flesh, liver and eggs were below $5 \%$ and it was below detection limits in kidney while the concentration in the gills is around $20 \%$ before recovery above $5 \%$ after recovery. The concentration of $\mathrm{Cu}$ in various part of the fish changes upon addition of $\mathrm{Zn}$, the concentration of $\mathrm{Cu}$ in eggs is the least, then kidney, liver, gills and flesh but during recovery it loses visually all the Cu present in the flesh and the amount present in other reduced although the concentration of $\mathrm{Cu}$ in the Kidney is practically the same. For $\mathrm{Zn}$, liver accumulated the highest amount followed by eggs, flesh, gills and kidney after recovery amount of $\mathrm{Zn}$ in all parts reduces with highest reduction in flesh and eggs. 


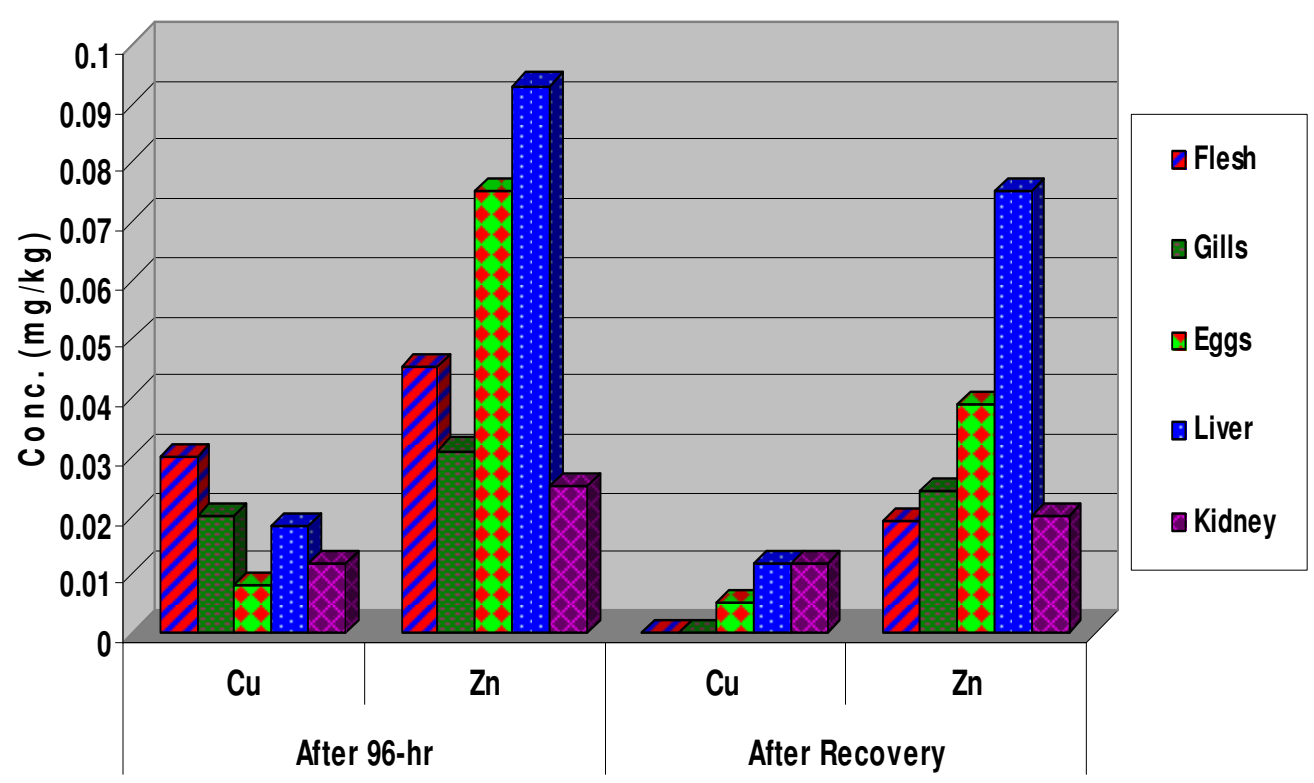

Fig.3.2 Distribution of mixture of $\mathrm{Cu}$ and $\mathrm{Zn}$ in fish before and after recovery

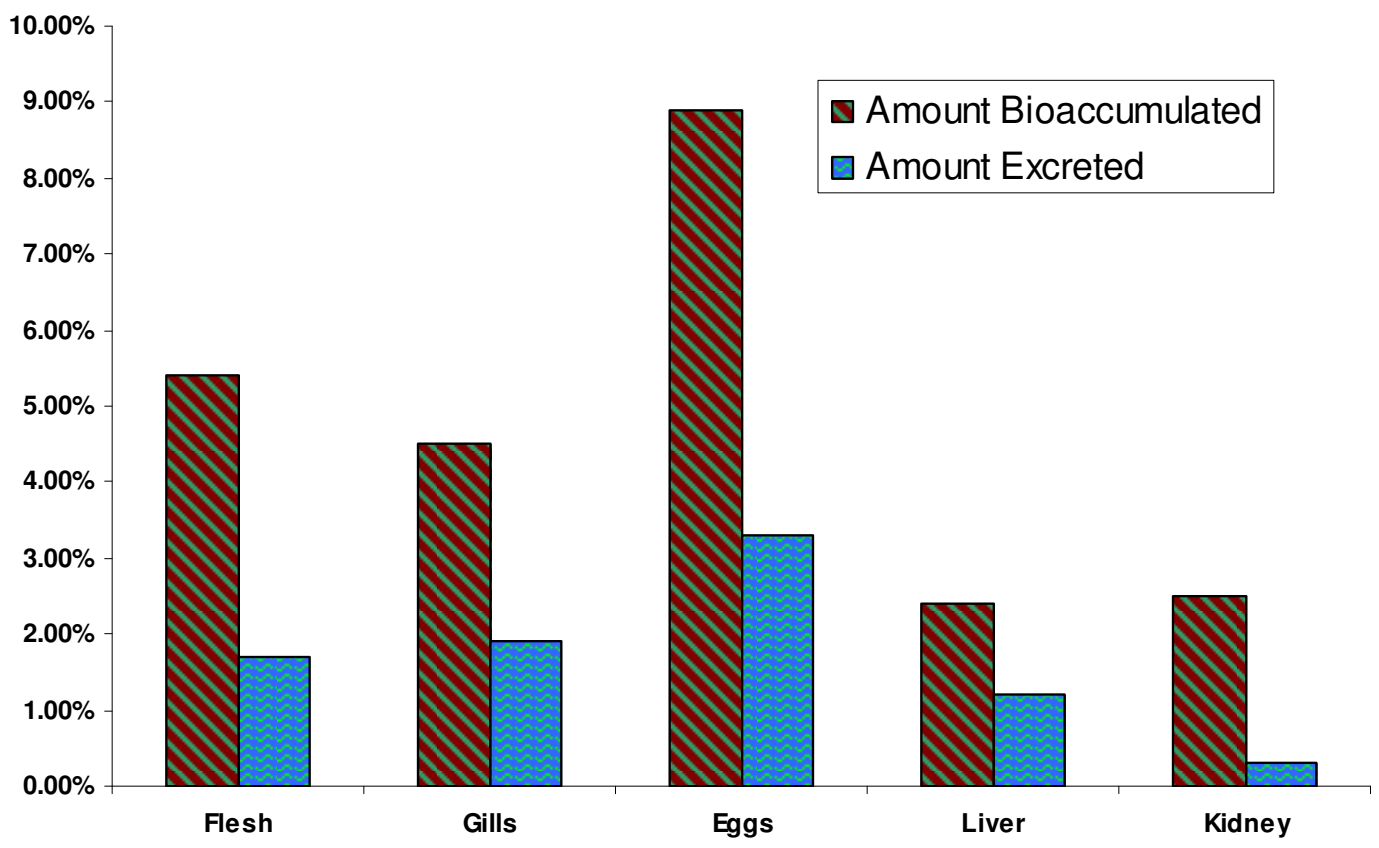

Fig. 3.3 Percent $\mathrm{Pb}$ bioaccumulated and excreted in fish 


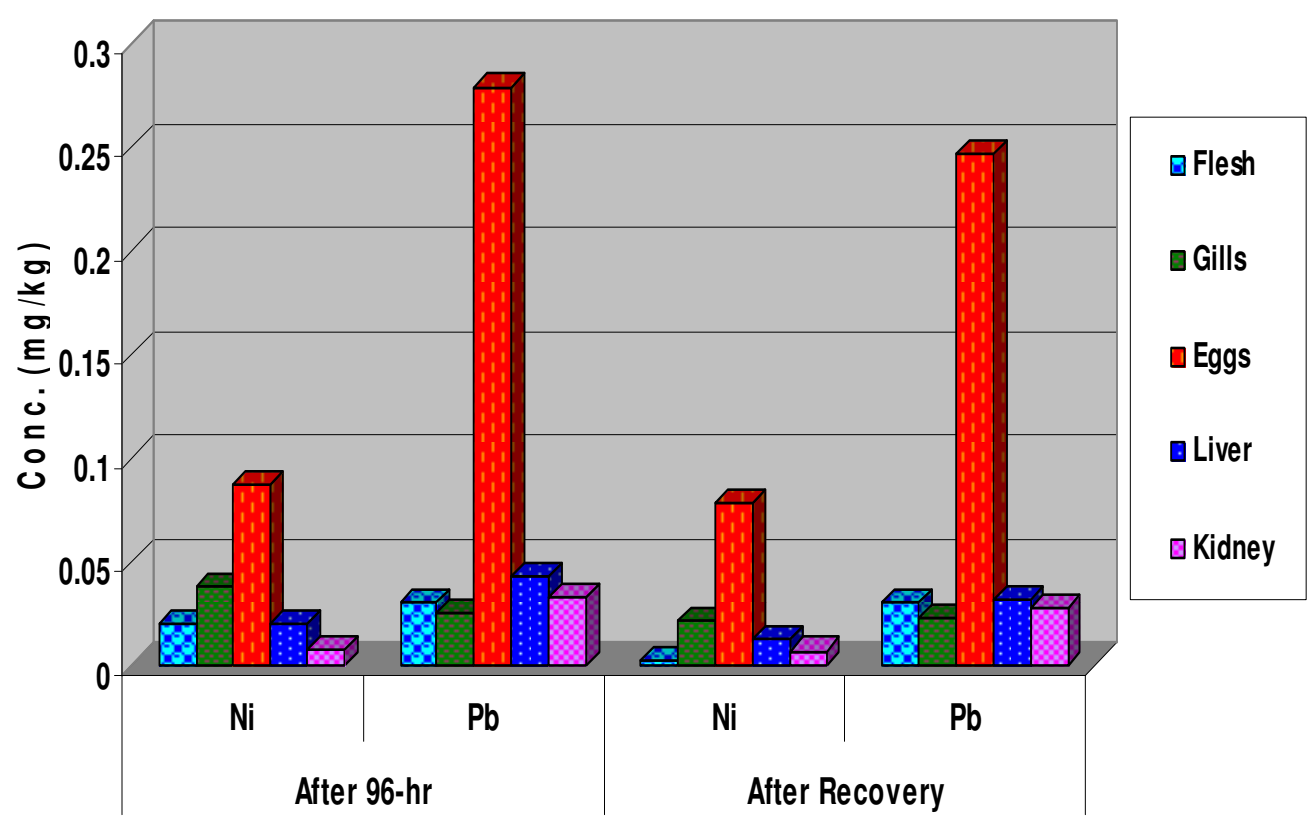

Fig.3.4 Distribution of mixture of $\mathrm{Ni}$ and $\mathrm{Pb}$ in fish before and after recovery

From Fig.3.3 the eggs had the highest concentration of $\mathrm{Pb}$ bioaccumulated and excreted. fig. 3.4 also confirmed eggs to contain highest concentration of $\mathrm{Pb}$ which reduced during recovery. It can also be seen that amount of lead in flesh is the same after recovery, every other information are very clear in the figures, the amount of $\mathrm{Pb}$ in the fish were relatively constant after recovery meaning that even after recovery $\mathrm{Pb}$ is present in fish body.

\section{CONCLUSION}

It can be seen from the above results that the amount of the selected heavy metals singly and in mixture is very small in fish body and that each heavy metals are attached to different part of the fish with different degree of affinity. It can also be concluded that $\mathrm{Cu}$ and $\mathrm{Ni}$ easily leaves flesh after recovery but $\mathrm{Pb}$ and $\mathrm{Zn}$ were attached to the flesh. Caution must be taken when eaten fish from contaminated site or when eaten fishes kills with Chemicals because some of these heavy metals and other chemicals will be attached to different part of the fish even upon serious washing.

\section{REFERENCES}

Y.H Lee, and R.R Stubieng Bull. Environ. Contam. Toxicol ., 45(1990), pp272-279.

Gumgum E,Unlu, Ztez, Z. Glsun, Chemosphere 29(1)(1994)pp111-116.

Balkas,T.I, S.Tungrul and I. salihoglu(1982) Mar. Environ. Res., 6:281-289.

Gurel Turkmen(2012) J.Ani. Vert. Adv.11(15):23892844.

Kori-siakpere O(1995). Bioscience Res. Commun. 8(20) 93-98.

American Public Health Association (APHA) (1998). Standard methods for Examination of waste water and water. APHA inc. Washington DC $20^{\text {th }}$ Edition.

Cite this Article: Oloye FF, Ololadea IA, Oluwolea OD and Oluyedeb OP (2013). Evaluating the Potential of African Catfish (Clarias gariepinus) to Bioaccmulation of Some Selected Heavy Metals. Greener Journal of Agricultural Sciences, 3(10): 687691, http://doi.org/10.15580/GJAS.2013.10.083013809. 